The inverse of the coefficient matrix in [B.1] is

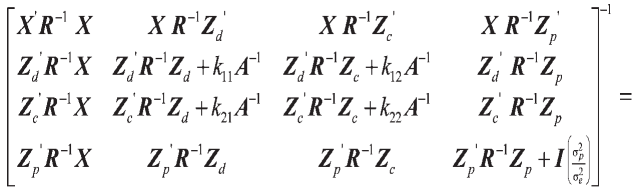

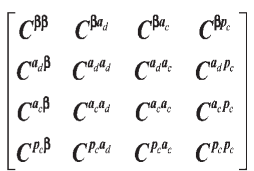

Then, the REML-EM estimating equations of the dispersion parameters in the $k^{\text {th }}$ iteration are

$$
\begin{aligned}
& \hat{\sigma}_{\mathrm{A} d}^{2[k]}=\frac{\left[\hat{\boldsymbol{a}}_{d}{ }^{\prime} \boldsymbol{A}^{-1} \hat{\boldsymbol{a}}_{d}\right]^{[k]}+\operatorname{tr}\left(A^{-1} \boldsymbol{C}^{a_{d} \boldsymbol{a}_{d}}\right) \hat{\boldsymbol{\sigma}}_{e}^{[k-1]}}{q} \\
& \hat{\sigma}_{\mathrm{Ac}}^{2[k]}=\frac{\left[\hat{\boldsymbol{a}}_{c}^{\prime} A^{-1} \hat{\boldsymbol{a}}_{c}\right]^{[k]}+\operatorname{tr}\left(A^{-1} C^{a_{c} a_{c}}\right) \hat{\sigma}_{e}^{2[k-1]}}{q}
\end{aligned}
$$

$$
\begin{array}{r}
\hat{\sigma}_{\text {AcAd }}[k]=\frac{\left[\hat{\boldsymbol{a}}_{d}^{\prime} A^{-1} \hat{\boldsymbol{a}}_{c}\right]^{[k]}+\operatorname{tr}\left(\boldsymbol{A}^{-1} \boldsymbol{C}^{a_{c} \boldsymbol{a}_{d}}\right) \hat{\boldsymbol{\sigma}}_{e}^{2[k-1]}}{q} \\
\hat{\sigma}_{p}^{[k]}=\frac{\left[\hat{\boldsymbol{p}}_{c}^{\prime} \hat{\boldsymbol{p}}_{c}\right]^{[k]}+\operatorname{tr}\left(\boldsymbol{C}^{p_{c} p_{c}}\right) \hat{\sigma}_{e}^{2[k-1]}}{n} \\
\hat{\sigma}_{e}^{2[k]}=\frac{\left[\hat{\boldsymbol{e}}^{\prime} \hat{\boldsymbol{e}}\right]^{[k]}+\left(p+2 q-f^{[k]} \hat{\sigma}_{e}^{2[k-1]}\right) \hat{\sigma}_{e}^{[k-1]}}{n} \\
\text { where } \hat{\boldsymbol{e}}^{[k]}=\boldsymbol{y}-\boldsymbol{X} \hat{\boldsymbol{\beta}}^{[k]}-\boldsymbol{Z}_{d} \hat{\boldsymbol{a}}_{d}^{[k]}-\boldsymbol{Z}_{c} \hat{\boldsymbol{a}}_{c}^{[k]}-\boldsymbol{Z}_{p} \hat{\boldsymbol{p}}_{c}^{[k]}, \text { and } \\
f^{[k]}=\left[\operatorname{tr}\left(\boldsymbol{A}^{-1} \boldsymbol{C}^{d d}\right) g^{d d}+2 \operatorname{tr}\left(\boldsymbol{A}^{-1} \boldsymbol{C}^{d c}\right) g^{d c}+\operatorname{tr}\left(\boldsymbol{A}^{-1} \boldsymbol{C}^{c c}\right) g^{c c}+\operatorname{tr}\left(\boldsymbol{C}^{p_{c} p_{c}}\right) \hat{\boldsymbol{\sigma}}_{p}^{-2}\right] \\
\text { with } \boldsymbol{G}_{0}^{-1}=\left[\begin{array}{ll}
g^{d d} & g^{d c} \\
g^{c d} & g^{c c}
\end{array}\right] .
\end{array}
$$

\title{
Inheritance and Genetic Gain in Wood Stiffness in Radiata Pine Assessed Acoustically in Young Standing Trees
}

\author{
By A. C. MATHESON ${ }^{1)}$, W. J. GAPARE ${ }^{1),}{ }^{*}$, J. Ilic $^{2)}$ and H. X. WU ${ }^{1)}$ \\ (Received $5^{\text {th }}$ October 2006)
}

\begin{abstract}
Wood stiffness, measured in terms of its modulus of elasticity $(\mathrm{MoE})$ is an important characteristic of radiata pine for structural products. To select high stiffness radiata pine for breeding purpose, rapid, inexpensive methods for measuring wood stiffness are desirable. In this study, we explored acoustic instruments to measure stiffness of young standing trees in radiata pine and examined inheritance and genetic gain for stiffness in an Australian national breeding program. Time of flight of sound waves was recorded in standing trees in two progeny trials, one in eastern Victoria (Flynn) aged 8 years and the other in South Australia (Kromelite) aged 7 years. Average time of flight at Kromelite was higher than at Flynn, (519 $\mu \mathrm{s} /$ metre compared to $463 \mu \mathrm{s} /$ metre) which corresponds to $3.7 \mathrm{GPa}$ and $4.7 \mathrm{GPa}$ for $\mathrm{MoE}$, respectively. Heritability for time of flight was higher at Flynn $\left(h^{2}=0.67 \pm 0.10\right)$ than at Kromelite $\left(h^{2}=0.30 \pm\right.$ $0.14)$. Selection of the best $10 \%$ for time of flight based

1) Ensis ${ }^{3)}$, CSIRO Forestry and Forest Products, P. O. Box E4008, Canberra, ACT 2604, Australia.

2) Ensis, CSIRO Forestry and Forest Products, Private Bag 10, Clayton South, Victoria 3168, Australia.

${ }^{3}$ ) Ensis is a joint venture between CSIRO FFP P/L and Scion Australasia P/L.

*) Corresponding author: Telephone: +61-2-6281-8322, Fax: +612-6281-8312. E-Mail: $\underline{\text { Colin.Matheson@csiro.au }}$
\end{abstract}

on pooled data would result in $21 \%$ genetic gain in wood stiffness.

Key words: wood stiffness, acoustics, heritability, genetic gain, radiata pine.

\section{Introduction}

Australia has an advanced breeding program for Pinus radiata D. Don (Powell et al., 2005), which has over the last 50 years significantly improved many characteristics of this widely planted fast growing conifer (Matheson et al., 1986; CotTerill and DeAn, 1990; Wu et al., 2004). Traditionally trees have been selected based on visual qualities including diameter, height, branching, straightness, observable defects, age and site characteristics (WU and MATHESON, 2002). However, neither site nor these visual characteristics are good predictors of the mechanical properties of the wood products. In addition, as the main uses of the products are structural applications either as solid wood or as engineered wood products, there is a demand to plant trees with high stiffness. In the framework of a genetic improvement program, visually unobservable characteristics such as wood stiffness could be considered as selection criteria in the same way as growth or form, if they can be measured inexpensively, to maintain or improve the mechanical properties of wood produced. 
Wood stiffness, measured as its modulus of elasticity ( $\mathrm{MoE})$, is one of the most important mechanical properties for most end uses of wood-based biomaterials. Based on an industry survey, Ivković et al. (2006) recommended MoE as one of the major breeding objective traits for radiata pine in Australia. MoE has a significant impact on structural timber grade outturn. This is particularly driven by the aim to increase the recovery of structuraland appearance-grade products, which gives a higher economic return (DUNGEY et al., 2006). Unfortunately, in radiata pine, the juvenile wood (also called corewood), i.e., comprising anywhere from the first seven to the first 13 rings from the pith (GAPARE et al., 2006), often presents problems for utilisation due to the poorer mechanical properties and the high distortion. The lowstiffness wood zone becomes a strategic research topic for improving radiata pine wood quality in order to achieve shorter rotations with high stiffness wood.

In forest tree breeding, mature performance is customarily predicted using attributes measured in juvenile field trials. Selection at early ages can be expected to yield higher genetic gain per unit time than direct selection for harvest age performance if there are sizable age-age genetic correlations (e.g., MATHESON et al., 1994). The advantages of pre-rotation selection comprise easier measurement and lower costs per tree, and there is also a quicker incorporation of genetically improved materials into forest production. The optimum age for selection for growth and wood density in radiata pine is about age 6 (COTTERILL and DEAN, 1988; MATHESON et al., 1994; Li and Wu, 2005; Wu et al., 2007) at which age destructive sampling for wood properties is undesirable and expensive. KUMAR and LEE (2002) reported that early selection of wood density at core age 5 years in would be effective for family and individuals for age 30 years radiata pine trees in New Zealand. HYLEN (1999) reported very high genetic correlation between early ages and age 12 years in Norway spruce. Similarly, GWAZE et al. (2000) reported high age-age correlations between ages 5 and 25 years in loblolly pine. Nondestructive and cheaper surrogates for wood stiffness in standing trees would be an advantage for tree selection both for deployment and further breeding. To help capture the opportunities the potential stiffness of products needs to be identified at an early age of the trees.

Genetic variation for stiffness based on a direct bending test or using SilviScan prediction has been observed (MATHESON et al., 1997; SHELBOURNE et al., 1997; MATHESON and Dungey, 2003; Dungey et al., 2006). But direct measurement of the bending MoE (also known as the static MoE, usually performed on normalised specimens) requires destructive sampling and is expensive and time-consuming. While a direct measure of bending stiffness is the most accurate, indirect measures that are far less destructive and expensive are the most desirable for breeding purposes. Recent work has shown that stiffness can be indirectly measured by either using mechanical and chemical properties of wood or using component wood quality traits. SCHIMLECK et al. (2002) estimated wood stiffness of increment cores using nearinfrared spectroscopy. Instruments based on acoustic waves showed great promise for measuring stiffness of standing trees, logs (CARTER et al., 2005), small axial specimens from outer wood (CARTER et al., 2006; ILIC, 2003), and for log segregation in radiata pine (WALKER and NAKADA, 1999; MATHESON et al., 2002). Stiffness of wood is known to be related to dry-wood density, microfibril angle (MfA) and slope of grain arising from spiral grain (CAVE, 1969). Indirect prediction of stiffness using these component traits is therefore also possible (EvANS and Ilic, 2001).

The standing tree time-of-flight technique provides an acoustic wave velocity for the stem. The acoustic velocity is related to $\mathrm{MoE}$ of the wood according to the following equation:

$$
\mathrm{V}^{2}=\mathrm{MoE} / \mathrm{D}
$$

where:

$$
\begin{aligned}
\mathrm{V}= & \text { Velocity } \mathrm{m} / \mathrm{s}\left(\mathrm{V}=1 / \mathrm{T} ; \mathrm{T}=\text { time of flight }\left(\mathrm{s}^{-1}\right)\right) \\
\mathrm{MoE}= & \text { Modulus of elasticity }(\mathrm{Pa}) \\
\mathrm{D}= & \text { Green density }\left(\mathrm{kg} / \mathrm{m}^{3}\right), \text { usually assumed to be } \\
& 1000 \mathrm{~kg} / \mathrm{m}^{3} \text { for radiata pine (e.g., LASSERRE } \text { et } \\
& \text { al., 2004). }
\end{aligned}
$$

When MoE is measured in this way it is known as dynamic MoE in contrast to static MoE which is measured by bending. The dynamic and static measured MoE values are highly related in green and dry wood (Booker and Sorensson, 1999; Ilic, 2001).

The Southern Tree Breeding Association (STBA), which works cooperatively to breed and improve radiata pine for its 20 members, has now begun selection for the third-generation breeding population among trees in second-generation progeny tests planted in 1996 and 1997. Currently, there are no estimates of genetic parameters for wood stiffness based on acoustic measurements in Australian radiata pine. Wood density and microfibril angle are the key drivers of MoE in radiata pine, thus initial work to improve stiffness has been through improvement of these component traits (DUNGEY et al., 2006; BALtUNIS et al., 2007). However, direct improvement of MoE would be more efficient if $\mathrm{MoE}$ can be measured accurately. Previous work on small numbers of samples have shown high heritabilities of wood stiffness for New Zealand radiata pine based on acoustic measurements (KUMAR et al., 2002; KUMAR, 2004). Selection for MoE, using indirect methods such as acoustic measurements would remove the need to assess MfA through SilviScan in order to improve the stiffness of corewood in radiata pine. The objective of this study was to estimate the amount of genetic variability in wood stiffness from standing trees based on measuring the velocity of acoustic waves.

\section{Materials and Methods}

\section{Study material}

Two progeny trials (BR9611, located at Flynn, Victoria and managed by Hancock Victorian Plantations and BR9705, located at Kromelite, South Australia and managed by Green Triangle Forest Products) were selected for this study. These radiata pine tests are part of the progeny test series following controlled pollinations based on the Nucleus Breeding Strategy of WHITE 
et al. (1999). The broad objectives of the progeny test series were:

(i) provide genetic parameters needed for selection index development focusing on growth and wood quality traits;

(ii) provide groups of genetically connected progeny for use in advanced generation selections and breeding in Australia; and

(iii) provide rankings of families and individuals for use in forward selections for third generation breeding and testing.

The trials consisted of all families generated from crosses of the second generation selections. A mixed mating structure was used to generate full-, and half-sib families (WHITE et al., 1999).

Table 1. - Details of the Flynn (BR9611) and Kromelite (BR9705) sites used for this study.

\begin{tabular}{|c|c|c|}
\hline Details & Flynn & Kromelite \\
\hline Experiment number & BR9611 & BR9705 \\
\hline Date planted & 6/1996 & $7 / 1997$ \\
\hline Cambial age at time of sampling & 8 & 7 \\
\hline Spacing & $3.6 \mathrm{~m} \times 2.5 \mathrm{~m}$ & $2.7 \mathrm{~m} \times 2.5 \mathrm{~m}$ \\
\hline Latitude & $38^{\circ} 14^{\prime} S$ & $37^{\circ} 50^{\prime} \mathrm{S}$ \\
\hline Longitude & $146^{\circ} 45^{\prime} \mathrm{E}$ & $140^{\circ} 55^{\prime} \mathrm{E}$ \\
\hline Elevation (m) & 166 & 55 \\
\hline Annual rainfall $(\mathrm{mm})$ & 760 & 900 \\
\hline Soil type & Sandy loam & Sandy clay-loam \\
\hline Site type & $2^{\text {nd }}$ rotation & $2^{\text {nd }}$ rotation \\
\hline Total number of families & 250 & 110 \\
\hline Number of replicates & 5 & 3 \\
\hline $\begin{array}{l}\text { Number of columns within } \\
\text { replicates }\end{array}$ & 25 & 11 \\
\hline Number of rows within a column & 10 & 10 \\
\hline
\end{tabular}

Flynn was planted in June, 1996 with 250 families, consisting of 88 polycoss families, 157 full-sib families, and 5 controls, planted in a $10 \times 25$ row-column design with 5 replicates and four-tree row plots. Kromelite was planted in July, 1997 with 110 families, consisting of 70 polycross families, 40 full-sib families with no controls, planted in a $10 \times 11$ row-column design with 5 replicates and four-tree row plots. Every third row at each site was an outrow. Both sites were second rotation radiata pine sites. These trials contained a total of 344 different families from both full-sib crosses from single-pair matings and half-sib families from polymix crosses derived from the STBA breeding population. Progenies from 41 common parents (including 16 full-sib families) were common to both sites.

\section{Preliminary study to identify optimal instrument for breeding purposes}

In order to determine the optimal instrument to measure tree stiffness in these trials, the following five acoustic and non-acoustic instruments were tested for the project:
Fakopp stress wave timer ${ }^{1)}$ (www.fakopp.com). This involves inserting two probes, each with a sensor. The bottom probe is tapped with a small hammer and the time for the stress wave to travel between the probes is measured. The distance between probes is usually about $1 \mathrm{~m}$, but must be known accurately. Fakopp was used only on one side of the tree because there was essentially no difference between readings taken on opposite sides of the tree.

IML Hammer stress wave timer (www.walesch.ch). This involves inserting two generic probes (initially screws) and attaching a sensor to the top probe. The bottom probe is tapped with the IML hammer. The IML hammer contains a strain gauge to detect the initiation of the stress wave. The travel time of the stress wave is measured and so the distance between the probes must be known and is usually about $1 \mathrm{~m}$. The IML was used on two opposite sides of the trees.

Krautkramer USD10-NS Ultrasound flaw detector (www.geinspectiontechnologies.com). This involves inserting two probes a known distance apart and applying ultrasound waves to the bottom probe and timing their arrival at the top probe. Because the wavelength is small, it is necessary to avoid branches and insert the probes in clear wood. Probes are typically about $300 \mathrm{~mm}$ apart.

Tree sway. This involved manually swaying the trees and filming the frequency of sway with a digital movie camera. The movie is viewed frame-by-frame to determine the frequency of sway.

Dynamic MoE of axial beams. This involves cutting axial specimens approximately $120 \mathrm{~mm}$ x 10-15 mm x $2 \mathrm{~mm}$ from the outerwood of a tree. In this case, they were cut from discs removed from the logs during the sampling process. These are tested directly in the laboratory for dynamic MoE (ILIC, 2003).

These measurements on standing trees were compared with benchmark measurements based on logs cut down from the same trees and using following two instrument:

Director HM200 (www.fibre-gen.com). This is an instrument developed by $\mathrm{CCH}$ Fibre-gen as a variation of Hitman to segregate logs based on their resonance. Director is placed against the lower cut surface and the $\log$ is hit with a hammer. The resonant frequency is detected with a microphone and recorded.

HP Dual Channel Dynamic Signal Analyzer 35665A. This is an off-the-shelf product and works in a manner analogous to the Director HM200. Its microphone detects resonances from the log and displays it with detected harmonics on a screen. The dominant harmonic can be determined visually and its frequency recorded.

Thirty-eight trees in outrows between treatment trees at the Flynn site were used to compare measurements made by each technique in December 2003. Lower branches were first cut off with an axe and a Fakopp measurement made on one side of the tree with probes $1 \mathrm{~m}$ apart, avoiding placing probes into branch whorls.

\footnotetext{
1) Mention of a commercial product in no way implies endorsement of the product.
} 
An IML measurement was then made using the same holes as the Fakopp on one side of the tree and a further measurement was made on the opposite side of the tree with probes again $1 \mathrm{~m}$ apart. An Ultrasound measurement was then made on a portion of the stem $300 \mathrm{~mm}$ long between the two Fakopp probe holes and not encompassing branch stubs. Trees were then manually swayed and the decay of the swaying recorded on a digital camcorder. The tree was then cut down, the log length measured and a disc about $150 \mathrm{~mm}$ thick taken at $2 / 3$ of the tree height. A Director measurement was then taken on the log representing $2 / 3$ of the tree height, followed by an HP signal analyser measurement. Axial specimens were cut from the discs in the laboratory and tested for dynamic MoE as described in ILIC (2003). The two measurements on logs were carried out a few weeks later than the others due to a fault in the HP signal analyser at the time measurements were taken on standing trees.

Pairwise product-moment correlation coefficients were calculated between measurements obtained for each tree. Correlations from this preliminary study are given in Table 2.

Table 2. - Correlations between $\mathrm{MoE}$ measurements by different instruments on 38 trees from outrows in the Flynn trial.

\begin{tabular}{|c|c|c|c|c|c|c|}
\hline & Fakopp & IML & Ultrasound & Sway & Director & $\mathrm{HP}$ \\
\hline IML & 0.89 & 1.00 & & & & \\
\hline Ultrasound & $d 0.25$ & 0.43 & 1.00 & & & \\
\hline Sway & 0.39 & 0.55 & 0.56 & 1.00 & & \\
\hline Director & 0.85 & 0.94 & 0.25 & 0.42 & 1.00 & \\
\hline HP & 0.84 & 0.94 & 0.27 & 0.45 & 0.95 & 1.00 \\
\hline Axial beam & $\mathrm{n} 0.70$ & 0.70 & 0.41 & 0.64 & 0.64 & 0.58 \\
\hline
\end{tabular}

For two logs, the HP Signal Analyzer corrected the Director result which had selected the incorrect harmonic. Results included the corrected values rather than the originals. The IML results are for the average of measurements taken on the two sides of the tree.

The Director was regarded as the main benchmark, partly because it is used in industry. Table 2 indicated that the IML was the most accurate $(r=0.94$ with the Director). Correlations between the two IML measurements taken separately and the Director were 0.90 and 0.92. IML also showed a high correlation with HP (0.94). Consequently, it was resolved to measure stiffness in the progeny tests using the IML hammer on one side of the tree to optimise cost and accuracy.

\section{Measurements}

For the purpose of this study, acoustic measurements were recorded for two trees in each plot of all five replicates at Flynn. At Kromelite, acoustic measurements were recorded for all four trees in three of the five replicates. The IML Electronic Hammer (Instrumenta Mechanik Labor $\mathrm{GmbH}$ ) was used to measure the time of flight. The two probes in IML were modified from the original screw probes so they could be hammered into trees rather then being screwed. This was done to save time and was done after comparison with other methods. Use of screws or modified probes does yield similar results. The bottom probe was hammered into a measurement tree, angled upwards at about $45^{\circ}$. The top probe was hammered into the tree $1 \mathrm{~m}$ above the lower probe and angled downwards at $45^{\circ}$. A metal sleeve was used when hammering in the upper probe to avoid damaging the threaded hole in the probe. The detector was screwed into the top probe and connected to the electronic timer box. The special hammer was also connected to the electronic timer box. The bottom probe was tapped with the special hammer a number of times and the time of flight displayed for each tap by the electronic box in microseconds ( $\mu \mathrm{s})$. When a consistent reading was obtained, that reading was recorded.

\section{Methodology for data analysis}

\section{Traits}

Assuming the density of green wood is $1000 \mathrm{~kg} / \mathrm{m}^{3}$, the Modulus of Elasticity can be calculated approximately as $\mathrm{V}^{2} / 10^{6}$ in $\mathrm{GPa}$ where $\mathrm{V}$ is the velocity of the stress wave in the tree (in $\mathrm{m} / \mathrm{s}$ ). Examination of residuals for velocity suggested that transformation would be required. For this reason and because the above calculation of MoE from velocity applies only over longer distances than used here (ANDREWS, 2002), only time of flight was analysed. Time of flight could be regarded itself as an indication of MoE. Longer flight times are associated with lower stiffness values. Unless explicitly stated, analyses of DBH (provided by STBA) were conducted only for trees which had a time-of-flight measurement.

\section{Individual sites}

Data were analysed using an individual tree model (BORRALHO, 1995) with genetic founder groups (QUAAS, 1988; WeSTELL et al., 1988) in the restricted maximum likelihood (REML) statistical program ASReml (GILMOUR et al., 2005), adjusting for incomplete row and column effects. Block effects and genetic founder groups were regarded as fixed and other effects considered random. The genetic founder groups describe whether the ancestors of the parent trees in the trials were:

i) pre- or post-1970 selections, in Australia or New Zealand,

ii) elite selections or not

iii) breeding line (A or B)

iv) the part of the line from which they were drawn (Nucleus or Main) as described above.

Individual tree models in ASReml (GILMOUR et al., 2005) involve the development of a relationship matrix from a supplied pedigree file in which the ancestry of every individual in the trial(s) is described. This is extremely flexible and enables estimates of genetic parameters from very diverse trials such as these in which some genetic entries were the result of polycrosses and some were full-sibs. Most genetic analysis computer programs would require families to be divided into groups with common genetic structure (i.e., separate polycrosses from full-sibs) so appropriate coefficients of relationship can be applied to variance components 
when estimating genetic parameters. The linear format of the full model used for analyses within each site was:

$$
\mathbf{y}=\mathbf{X b}+\mathbf{Z}_{1} \mathbf{a}+\mathbf{Z}_{2} \mathbf{s}+\mathbf{W}_{1} \mathbf{m}+\mathbf{W}_{2} \mathbf{p}+\mathbf{e}
$$

where $y$ is the vector of individual tree observations; $\mathbf{b}$ is the vector of fixed effects (i.e., genetic groups, replicates); $\mathbf{a}$ is the vector of random general combining ability (GCA) effects of individual trees; $\mathbf{s}$ is the vector of random specific combining ability (SCA) effects due to non-additive genetic effects containing dominance and some epistatic effects; $\mathbf{m}$ is the vector of random effects due to rows and columns within replicates; $\mathbf{p}$ is the vector of random plot effects; $\mathbf{e}$ is the vector of random residual deviations of individual trees; $\mathbf{X}, \mathbf{Z}_{1}, \mathbf{Z}_{2}, \mathbf{W}_{1}$ and $\mathbf{W}_{2}$ are incidence matrices relating to the model effects. It is assumed that the random terms are jointly normal with moments:

$$
\begin{aligned}
& E(\mathrm{a})=E(\mathrm{~s})=E(\mathrm{~m})=E(\mathrm{p})=E(\mathrm{e})=0 \\
& \operatorname{VAR}\left[\begin{array}{l}
a \\
s \\
m \\
p \\
e
\end{array}\right]=\mathrm{A} \sigma_{a}^{2} \oplus \mathrm{I} \sigma_{s}^{2} \oplus \mathrm{I} \sigma_{m}^{2} \oplus \mathrm{I} \sigma_{p}^{2} \oplus \mathrm{I} \sigma_{e}^{2}
\end{aligned}
$$

where $\oplus$ is the direct sum of matrices related to the random terms in the model; $\mathbf{A}$ is the additive genetic relationship matrix between trees and $\mathbf{I}$ is an identity matrix; $\sigma^{2}{ }_{a}$ is the additive genetic variance; $\sigma^{2}$ is the variance due to non-additive genetic effects containing dominance and some epistatic effects; $\sigma_{\mathrm{m}}^{2}$ is the variance from rows and columns within replicates, $\sigma_{p}^{2}$ is the variance from plots effects; $\sigma^{2}$ is the residual variance.

Individual-tree narrow-sense heritabilities were estimated at the within-site level as:

$$
h^{2}=\frac{\sigma_{a}^{2}}{\sigma_{a}^{2}+\sigma_{s}^{2}+\sigma_{p}^{2}+\sigma_{e}^{2}}
$$

in which $\sigma^{2}{ }_{a}, \sigma_{s}^{2}, \sigma_{p}^{2}$, and $\sigma^{2}$ represent the additive genetic, specific combining ability, plot and residual variances, respectively. Neglecting higher order epistatic interactions, the SCA variance is $0.25 \mathrm{x}$ non-additive variance (BECKER, 1984) and the sum of the plot and residual variances estimates $0.75 \mathrm{x}$ non-additive variance + environmental variance. Standard errors were calculated as in GiLmour et al. (2005). Rows and column effects are not included in the phenotypic variance (the denominator) because it is assumed selection will be made on data adjusted for rows and columns effects (WILliams et al., 2002).

\section{Genetic correlation with stem diameter}

A file containing diameters from an earlier measurement of diameter at breast height (DBH), measured on 6 June 2004 was obtained from STBA. Genetic correlations between time of flight and $\mathrm{DBH}$ at Flynn and Kromelite were obtained as follows:

$$
r_{A_{x y}}=\frac{C_{A_{x y}}}{\sqrt{V_{A_{x}} V_{A_{y}}}}
$$

in which $C_{A_{x y}}$ represents the additive covariance component between traits $x$, being time of flight and $y$ being $\mathrm{DBH}, V_{A_{x}}$ and $V_{A_{y}}$ represent the additive variance components for traits $x$ and $y$ respectively. Standard errors were calculated as in GILMOUR et al. (2005).

Correlated change in stem diameter (DBH) following selection for lower time of flight was calculated from the bivariate analysis (see eq 6) of both traits as:

$$
C R=i h_{d} h_{t} r_{A_{d t}} \sigma_{P_{d}}
$$

where $\mathrm{i}$ is the intensity of selection, $h_{d}$ and $h_{t}$ are the square roots of heritabilities for diameter and time of flight respectively, $r_{A_{d t}}$ is the additive genetic correlation between stem diameter and time of flight and $\sigma_{P_{d}}$ is the phenotypic standard deviation for stem diameter.

\section{Combined analyses}

Two models were fitted; one to estimate the additive and non-additive genetic correlations between sites and the other to provide estimates of breeding values of individual trees for selection purposes that were comparable across sites. The first was a bivariate model (eq 6) in which the times of flight at each site were treated as different traits. Effects for site, genetic group and replicate within site were treated as fixed while other effects (rows and columns within replicates at each site separately, plots at each site separately, SCA and additive effects for each site separately and with a covariance term) were treated as random. This initial model can be summarised as:

$$
\begin{aligned}
& {\left[\begin{array}{l}
y_{i} \\
y_{j}
\end{array}\right]=\left[\begin{array}{cc}
\mathbf{X}_{i} & 0 \\
0 & \mathbf{X}_{j}
\end{array}\right]\left[\begin{array}{c}
\mathbf{b}_{i} \\
\mathbf{b}_{j}
\end{array}\right]+\left[\begin{array}{cc}
\mathbf{Z}_{1 i} & 0 \\
0 & \mathbf{Z}_{1 j}
\end{array}\right]\left[\begin{array}{l}
\mathbf{a}_{i} \\
\mathbf{a}_{j}
\end{array}\right]+\left[\begin{array}{cc}
\mathbf{Z}_{2 i} & 0 \\
0 & \mathbf{Z}_{2 j}
\end{array}\right]\left[\begin{array}{l}
\mathbf{s}_{i} \\
\mathbf{s}_{j}
\end{array}\right]+} \\
& {\left[\begin{array}{cc}
\mathbf{W}_{1 i} & 0 \\
0 & \mathbf{W}_{1 j}
\end{array}\right]\left[\begin{array}{c}
m_{i} \\
m_{j}
\end{array}\right]+\left[\begin{array}{cc}
W_{2 i} & 0 \\
0 & W_{21 j}
\end{array}\right]\left[\begin{array}{l}
p_{i} \\
p_{j}
\end{array}\right]+\left[\begin{array}{l}
e_{i} \\
e_{j}
\end{array}\right]}
\end{aligned}
$$

where $y_{i}$ and $y_{j}$ are respectively, the vectors of individual tree observations in site $i$ (Flynn) and $j$ (Kromelite); the b vectors refer to fixed effects (genetic groups and replicates); $\mathbf{a}, \mathbf{s}, \mathbf{m}, \mathbf{p}$, e correspond to random effects, and $\mathbf{X}$, $\mathbf{Z}_{1}, \mathbf{Z}_{2}, \mathrm{~W}_{1}, \mathrm{~W}_{2}$ are incident matrices, all defined as before (see $\mathrm{Eq} 2$ ). On the assumption of multivariate normality, the random terms in model (6) have expectations

$$
\boldsymbol{E}\left[\begin{array}{l}
\mathbf{a}_{i} \\
\mathbf{a}_{j}
\end{array}\right]=\boldsymbol{E}\left[\begin{array}{l}
\mathbf{s}_{i} \\
\mathbf{s}_{j}
\end{array}\right]=\boldsymbol{E}[]=\left[\begin{array}{l}
\mathbf{s}_{i} \\
\mathbf{s}_{j}
\end{array}\right]=\boldsymbol{E}\left[\begin{array}{l}
m_{i} \\
m_{j}
\end{array}\right]=\boldsymbol{E}\left[\begin{array}{l}
p_{i} \\
p_{j}
\end{array}\right]=0
$$

and a variance-covariance matrix defined as

$$
\begin{aligned}
& {\left[\begin{array}{cc}
\mathrm{A} \sigma_{a i i}^{2} & \mathrm{~A} \sigma_{a i j} \\
\mathrm{~A} A \sigma_{a i j} & \mathrm{~A} \sigma^{2}{ }_{a, j}
\end{array}\right] \oplus\left[\begin{array}{cc}
I \sigma^{2}{ }_{s i i} & I \sigma_{s i j} \\
I \sigma_{s i j} & I \sigma^{2}{ }_{s i j}
\end{array}\right] \oplus\left[\begin{array}{cc}
I \sigma^{2}{ }_{m i i} & 0 \\
0 & I \sigma^{2}{ }_{m, j}
\end{array}\right]} \\
& \oplus\left[\begin{array}{cc}
I \sigma_{p_{i i}}^{2} & 0 \\
0 & I \sigma^{2}{ }_{p j i}
\end{array}\right] \oplus\left[\begin{array}{cc}
I \sigma^{2}{ }_{e i i} & 0 \\
0 & I \sigma_{e j i}^{2}
\end{array}\right]
\end{aligned}
$$

where the off-diagonal elements of the first two square matrices in the direct sum are covariances between trait measured in the two sites, namely due to additive effects $\left(\sigma_{a i j}^{2}\right)$ and due to effects related to the specific combining ability effects $\left(\sigma_{s i j}^{2}\right)$ expected to equal 0.25 of the dominance covariance (BECKER, 1984). The plot and residual effects were assumed to be uncorrelated across sites. 
To obtain a single set of breeding values across sites, data were pooled across sites and a univariate model was fitted (see eq 2 ) but with $\mathbf{b}$ being the vector of fixed effects (i.e., genetic groups, sites, replicates within sites) and all other terms as defined in eq 2 with SCA by site interaction term included in the model. Although the error variances from the two sites appeared different, the Akaike Information Criterion (AIC - see LYNCH and WALSH, 1998) for a model with a separate residual variance for each site was 11774.94 and for the model with a single residual variance the AIC was 11733.98 . For this reason, the single residual variance model was chosen as it was the most parsimonious. This pooled analysis meant that the BLUP estimates of breeding values for each tree at each site were comparable.

In all analyses, the rows and columns within replicates effects terms were dropped from the model when corresponding (co)variances were not significantly different from zero. This was determined on the basis of a component/standard error less than 1 , or by the log-likelihood-ratio test (GILMOUR et al., 2005) when the ratio component/standard error was between 1 and 2 .

\section{Results}

\section{Individual site analyses}

Flynn

The mean time of flight was $463 \mu$ s over one metre, corresponding to an velocity of $2160 \mathrm{~ms}^{-1}$ and an approximate $\mathrm{MoE}$ of approximately $4.7 \mathrm{GPa}$. Mean diameter was $15.4 \mathrm{~cm}$. Results from the analyses are presented in Table 3. All the variance components were significant except for the plot effect in $\mathrm{DBH}$. In this analysis, the non-additive variance $\left(\sigma_{\mathrm{s}}^{2}\right)$ was estimated as four times the SCA variance component. The non-additive variance (194) at FLYNN was a little over $15 \%$ of the additive variance (1280). However, for $\mathrm{DBH}$, the non-additive variance (17) was over one third (37\%) of the additive variance (45). The heritability estimate for time of flight was high $(0.67 \pm 0.10)$, but was low for $\mathrm{DBH}(0.12 \pm$ 0.05) (Table 3).

\section{Gains from selection and genetic correlation with $\mathrm{DBH}$}

The genetic correlation between time of flight and $\mathrm{DBH}$ was $0.33 \pm 0.23$. This suggests that families (fullor half-sib) with long flight times (low MoE) also have

Table 3. - Genetic parameter estimates for time of flight (measured in $\mu s$ per metre) and DBH $(\mathrm{cm})$ at Flynn and Kromelite in Pinus radiata trees.

\begin{tabular}{l|ll|ll}
\hline & \multicolumn{2}{|c|}{ Flynn } & \multicolumn{2}{c}{ Kromelite } \\
\hline Variance & IML & DBH & IML & DBH \\
Component & $\left(\mu \mathrm{sm}^{-1}\right)$ & $(\mathrm{cm})$ & $\left(\mu \mathrm{sm}^{-1}\right)$ & $(\mathrm{cm})$ \\
\hline$\sigma^{2}{ }_{a}$ & $1280^{*}$ & $45^{*}$ & $692^{*}$ & 63.4 \\
$\sigma_{\mathrm{s}}^{2}$ & $194^{*}$ & $17^{*}$ & $105^{*}$ & $\mathrm{~ns}$ \\
$\sigma^{2}$ & $172^{*}$ & $13^{\mathrm{ns}}$ & $277^{*}$ & $\mathrm{~ns}$ \\
$\sigma^{2}$ & $443^{*}$ & 299 & $1523^{*}$ & 399 \\
$\mathrm{~h}^{2}$ & $0.67 \pm 0.10$ & $0.12 \pm 0.05$ & $0.30 \pm 0.14$ & $0.14 \pm 0.06$ \\
Trait Mean & 463 & 15.4 & 519 & 17.0
\end{tabular}

* significant at $\mathrm{p}<0.05 ; \mathrm{ns}$ not significant at $\mathrm{p}<0.05$. large diameters and hence that wood stiffness and $\mathrm{DBH}$ are negatively genetically correlated at Flynn. Selection of the best $10 \%$ for time of flight would result in a decrease of $11.6 \%$ in time of flight, corresponding to an increase in stiffness of approximately $1.3 \mathrm{GPa}$, accompanied by a loss of DBH of $1.7 \%(0.27 \mathrm{~cm}$ out of $15.4 \mathrm{~cm})$.

\section{Kromelite}

The mean time of flight was $519 \mu \mathrm{s}$, corresponding to a velocity of $1927 \mathrm{~ms}^{-1}$ and an approximate MoE of approximately $3.7 \mathrm{GPa}$. The mean diameter was 17.0 $\mathrm{cm}$, larger than at Flynn even though trees were a year younger. Both the additive $\left(\sigma^{2}\right)$ and non-additive variance $\left(\sigma_{\mathrm{s}}^{2}\right)$ were found to be significant for time of flight at $p<0.05$. The heritability estimate for time of flight $(0.30 \pm 0.09)$ was clearly less than at Flynn $(0.67 \pm 0.10)$. The heritability for $\mathrm{DBH}$ was almost the same at Kromelite as for Flynn $(0.14 \pm 0.06$ cf $0.12 \pm 0.05)$.

Gains from selection and genetic correlations with $\mathrm{DBH}$

The genetic correlation between time of flight and $\mathrm{DBH}$ was $-0.12 \pm 0.21$, opposite in sign from that at Flynn, but with a large standard error and hence not significantly different from 0 . Selection of the best $10 \%$ for time of flight would result in a decrease of $7.2 \%$ in time of flight, corresponding to an increase in stiffness of approximately $0.6 \mathrm{GPa}$.

\section{Combined analysis}

Results from the combined analysis are presented in Table 2. There was a significant difference at $\mathrm{p}<0.05$, between the sites for time of flight, Flynn having a predicted mean time of flight $56.3 \mu$ s lower than Kromelite (463 $\mu \mathrm{s}$ vs $519 \mu \mathrm{s}$ ), corresponding to a difference of approximately $0.96 \mathrm{GPa}$ in MoE. Heritability for time of flight from the pooled analysis was $0.53 \pm 0.07$.

The additive genetic correlation between time of flight and stem diameter across both sites was 0.04 \pm 0.20 . The additive genetic correlation $\left(\mathrm{r}_{\mathrm{G}}\right)$ for time of flight between the sites was $0.95 \pm 0.09$. The phenotypic correlation between predicted family mean times of flight at each site for the common 16 full-sib families derived from 41 common parents was 0.81 . In addition to the common families, there was more genetic connection through common parents and grandparents for some other families.

Predicted gain was calculated from selecting the $10 \%$ of trees with the highest predicted breeding values from the pooled-site analysis. This was estimated to decrease the time of flight by $44 \mu \mathrm{s} /$ metre, corresponding to an increase in stiffness of approximately $0.90 \mathrm{GPa}$, a gain of $21.0 \%$.

\section{Discussion \\ Choice of acoustic tool}

Acoustic means of measuring wood stiffness in logs and cut wood pieces have existed for some time (e.g., BOOKER and SORENSSON, 1999; WALKER and NAKADA, 1999). Newer tools for measuring time of flight in standing trees have been adapted for measurements of wood 
stiffness and the latest tools have been designed for the purpose (CARTER, 2005; WANG et al., 2004).

The preliminary investigations reported here indicate that the acoustic tools all give very similar estimates of time of flight and hence approximate $\mathrm{MoE}$ in standing trees as was found by KUMAR (2004). Phenotypic correlations between the flight times and dynamic MoE measured in small axial beams were high for all acoustic tools, but highest for the tapping tools (Fakopp and IML). Both IML and Fakopp measured flight times over $1000 \mathrm{~mm}$ and sometimes encompassed branch whorls. The axial beams measured MoE over only a very short distance of clearwood (about $15.0 \mathrm{~cm}$ ) up the stem at 1.3 $\mathrm{m}$ above ground and so perfect correlation with the stress wave timers would not be expected.

Decisions about which tool to use are then based on convenience and consistency. Most tools involve an operator tapping a probe with a hammer. Our experience showed that this is a learned skill and differences in tapping technique lead to differences in times of flight even for the same operator. However, in this study, one operator was used for a whole block and only 2 operators were used at both sites. Changes in design of the tools to allow for a standard tapping force applied in exactly the same way would appear to be one way of reducing variability between techniques and between operators. The IML hammer has proved to be a workable field instrument for measuring time of flight in real situations. Using a team of 3 people per instrument it was possible to measure a young tree in these trials approximately each 40 seconds.

\section{Differences between sites}

Despite being a year younger, trees measured acoustically at Kromelite (average DBH $=17.0 \mathrm{~cm}$ ) were larger than those at Flynn (average DBH $=15.4 \mathrm{~cm}$ ). The average time of flight at Kromelite was higher than at Flynn, (average times $519 \mu \mathrm{s}$ cf $463 \mu \mathrm{s}$ ) corresponding approximately to $3.7 \mathrm{GPa}$ and $4.7 \mathrm{GPa}$ for $\mathrm{MoE}$, respectively. This was consistent with the positive genetic correlation between tree diameter and time of flight at Flynn (i.e. larger trees had longer flight times), suggesting that tree radial growth and wood stiffness are negatively genetically correlated. However, the lack of a significant genetic correlation at Kromelite indicates that this relationship, like other genetic parameters, depends on site and size of sample.

Our corresponding approximate $\mathrm{MoE}$ values are somewhat lower than those observed for the same material for MoE predicted from density (EvANS, 2003). BALTUNIS et al. (2007) reported an average $\mathrm{MoE}$ of $6.1 \mathrm{GPa}$ at Flynn and $4.5 \mathrm{GPa}$ at Kromelite. The discrepancy is likely to be due to the short distance over which the time of flight was measured so that the relationship between MoE and velocity (equation 1) does not exactly follow (see ANDREWs, 2002). Since acoustic tools measure stiffness of only the outer rings, we found the age-age correlations for MoE to be relatively high, above 0.87 from rings 1 to 6 (BALTUNIS et al., 2007).

In the analyses of separate sites, the heritability estimate for acoustic time of flight was higher at Flynn $\left(\mathrm{h}^{2}=0.67\right)$ than at Kromelite $\left(\mathrm{h}^{2}=0.30\right)$, primarily because the residual variance was lower (443 cf 1511). Although these residual variances appeared different, the Akaike Information Criterion indicated that a combined model with pooled residual variance was more parsimonious than one with separate residuals for each site. The within-site estimate of heritability for time of flight at Kromelite is similar to that obtained by KUMAR (2004) for a single site in New Zealand $\left(h^{2}=0.37\right)$, but that obtained at Flynn is considerably higher. It is possible that some environmental differences within the Kromelite site were not taken into account by the rowcolumn blocking structures. These structures appear to have been successful at accounting for trends at Flynn where there was a slope both between and within replicates so that columns would account for variation within replicates and replicates would account for the rest of the variation due to slope. There was apparently some variation within replicates across the slope because the variance component for rows was also significant. This was not so at Kromelite where none of the within-replicate blocking structures were significant. The site was level and apparently very uniform, but there could have been a patchy environment on a scale less than either rows or columns (GEZAN, 2005). This effect might also have been caused by only two trees per plot in all five replicates being measured at Flynn, but all four trees per plot measured in only three of the five replicates at Kromelite.

Low heritability traits such as $\mathrm{DBH}$ and shrinkage are generally sensitive to sample size per family (e.g., GAPARE et al., 2007). Genetic sampling effects might have played a role in the lower heritability estimates obtained for DBH at Flynn and Kromelite. 10 to 12 trees per family used in this study are not sufficient to estimate genetic correlations accurately for low-heritability traits. Because of its higher heritability for time of flight, the Flynn site would clearly be the preferred site to test and select for wood stiffness even though the trees were growing slower than at Kromelite. More sites would have to be used to make broader inferences about slower-growing sites providing a better testing environment.

\section{Results combined across sites}

The estimated heritability from the combined site analysis was 0.53 , lying between the estimates for the two sites taken separately. The gain $(21 \%)$ estimated from selection of only the best $10 \%$ of trees is considerable. The trees measured here were only 7 (at Kromelite) and 8 (Flynn) years old and so the wood being tested almost certainly would be defined as "corewood' (BuRdon et al., 2004). DungeY et al. (2006) found that there was considerable variation and high heritability estimates in wood stiffness in corewood, but less variation and lower heritability estimates in outerwood. Their estimates, one at a site in New Zealand and the other in NSW, Australia were very similar at age 8 . The extremely high values for both the additive genetic and the phenotypic correlation indicate the lack of additive $\mathrm{x}$ site interaction in this case. In fact, the additive genetic correlation between the sites was extremely high $\left(\mathrm{r}_{\mathrm{G}}=\right.$ $0.96 \pm 0.09)$. Similarly, Kumar (2004) reported an esti- 
mated genetic correlation of 0.94 between two sites in New Zealand for acoustic stiffness (measured on $5 \mathrm{~m}$ logs using a HitMAN). Johnson and GARTNER (2006) report an average type-B genetic correlation among sites of 0.85 for velocity in Douglas-fir aged 20 years. However, although there were common parents and grandparents, there were only 16 common families and this result should not be taken as definitive.

The average genetic correlation between $\mathrm{DBH}$ and density reported in 17 publications for radiata pine was -0.44 with a minimum of -0.08 to a maximum of -0.66 (Li and WU, 2005). Similarly, ATwood et al. (2002) reported a negative genetic correlation $(-0.34 \pm 0.16)$ between volume and specific gravity in loblolly pine. In this study, the genetic correlation between growth (dbh) and time-of flight was essentially zero across both sites $(0.33 \pm 0.23$ at Flynn and $-0.12 \pm 0.21$ at Kromelite $)$. This does not allow for a definitive conclusion about genetic correlations between growth and stiffness in this case. Elsewhere, reported negative genetic correlations between growth traits and wood stiffness should present some problems for selection in a breeding program. A suitable means to achieve this would be to construct a selection index aimed at maximising benefits from these two traits including not only their genetic parameters but also an estimate of the effects of each on the economic outcome for an appropriate breeding objective (see IVKović et al., 2006).

Comparison between static MoE (in boards or in special samples) and acoustic measures in standing trees should be explored to verify how good acoustic measurement in standing trees are at predicting stiffness of harvested boards.

\section{Conclusions}

- Heritabilities for the time of flight were high and there was no appreciable genotype $\mathrm{x}$ environment interaction between the two sites measured. This indicates that large gains in wood stiffness are possible in trees of this age.

- There appears to be no genetic correlation between growth and time of flight across both sites.

- The relationship between the acoustic measures of stiffness from the standing tree and more direct static or dynamic MoE measurements are required as an essential step.

\section{Acknowledgements}

This work forms part of the Juvenile Wood Initiative, a collaborative project between Ensis ${ }^{2)}$, STBA, FWPRDC and Arborgen. Acoustic measurements were carried out by Colin Matheson, Li Li, Washington Gapare, Milos IVković, AdAm REDMAN, ANDREw MoRRow and Winston LIEW of CSIRO-Forestry and Forest Products (now Ensis), Peter Buxton of HVP and Jill Duff of STBA.. We also thank two anonymous reviewers for the constructive suggestions on the earlier draft of the manuscript.

2) Ensis is a joint venture between Australia's CSIRO and New Zealand's SCION.

\section{References}

ANDREWs, M. (2002): Wood quality measurement - son et lumiere. NZ Jour. For. Res. 32: 19-21.

Atwood, R. A., T. L White and D. A. Huber (2002): Genetic parameters and gains for growth and wood properties in Florida source loblolly pine in the sourtheastern United States. Can. J. of For. Res 32: 1025-1038.

Baltunis, B., H. X. Wu and M. B. Powell (2007): Inheritance of density, microfibril angle and modulus of elasticity in the juvenile wood of Pinus radiata at two locations in Australia. Can. J. of For. Res (in press).

BECKER, W. A. (1984): Manual of Quantitative Genetics. $4^{\text {th }}$ ed. Academic Enterprises, Pullman, Washington.

Booker, R. E. and C. T. Sorensson (1999): New tools and techniques to determine mechanical wood properties. FIEA, Wood Quality Symposium, Emerging technologies for evaluating wood quality for wood processing, Melbourne, Dec. 1999.

Borralho, N. M. G. (1995): The impact of individual tree mixed models (BLUP) in tree breeding strategies. In: 'Eucalypt Plantations: improving fibre yield and quality' (Eds B. M. Potts, N. M. G. Borralho, J. B. Reid, R. N. Cromer, W. N. Tibbits and C. A. Raymond) pp 141-145 Proc CRCTHF-IUFRO Conference Hobart 19-24 Feb (CRC for Temperate Hardwood Forestry: Hobart).

Burdon, R. D., R. P. Kibblewhite, J. C. F. Walker, A. Robert, R. A. Megraw, R. Evans and D. J. Cown (2004): Juvenile Versus Mature Wood: A New Concept, Orthogonal to Corewood Versus Outerwood, with Special Reference to Pinus radiata and P. taeda. For. Sci. 50: $399-415$.

Carter, P., S. Chauhan and L. Walker (2005): Sorting logs and lumber for stiffness using Director HM200. Wood and Fiber Science 38: 49-54.

CAVE, I. D. (1969): The longitudinal modulus of Pinus radiata. Wood Sci. and Tech 3: 40-48.

Costa e Silva, J., N. M. Borralho and B. M. Potts (2004): Additive and non-additive genetic parameters from clonally replicated and seedling progenies of Eucalyptus globulus. Theor. Appl. Genet. 108: 1113-1119.

Cotterill, P. P. and C. A. Dean (1988): Changes in the genetic control of growth of radiata pine to 16 years and efficiencies of early selection. Silvae Genet. 37: 138-146.

Cotterill, P. P. and C. A. Dean (1990): Successful Tree Breeding with Index Selection. Division of Forestry and Forest Products, CSIRO, Australia.

Dungey, H. S., A. C. Matheson, D. Kain and R. Evans (2006): Genetics of wood stiffness and its component traits in Pinus radiata. Can. J. of For. Res 36: 1165-1178.

Evans, R. (2003): Wood stiffness by X-ray diffractometry. In: Proc. of the Workshop, Characterisation of the Cellulosic Cell Wall, Grand, Lake, Colorado, 25-27 August 2003. University of Iowa and the Society of Wood Science and Technology, Madison, Wisconsin, USA.

Evans, R. and J. ILIC (2001): Rapid prediction of wood stiffness from microfibril angle and density. For. Prod. Journal 51: 53-57.

Gapare, W. J., H. X. Wu and A. AbarqueZ (2006): Genetic control of the time of transition from juvenile to mature wood in Pinus radiata D. Don. Ann. For. Sci 63: 871-878.

Gapare, W. J., M. Ivković, M. B. Powell, T. A. McRae and H. X. WU (2007): Genetics of shrinkage in juvenile trees 
of Pinus radiata D. Don from two test sites in Australia. Silvae Genet. (in press).

Gwaze, D. P., F. E. Bridgwater, T. D. Byram, J. A. Woolliams and C. G. Williams (2000): Predicting ageage genetic correlations in tree-breeding programs: a case study of Pinus taeda L. Theor. Appl. Genet. 100: 199-206.

GEZAN, S. A. (2005): Optimal design and analysis of clonal forestry trials using simulated data. Unpublished $\mathrm{PhD}$ Thesis, University of Florida. 117pp.

Gilmour, A. R., B. J. Gogel, B. R. Cullis and R. ThompSON (2005): ASReml User Guide Release 2.0, VSN International Ltd, Hemel Hempstead HP1 1ES, UK.

Hylen, G. (1999): Age trends in genetic parameters of wood density in young Norway spruce. Can. J. For. Res. 29: 135-143.

ILIC, J. (2001): Relationship among the dynamic and static elastic properties of air-dry Eucalyptus delegatensis R. Baker. Holz als Roh- und Werkstoff 59: 169-175.

ILIC, J. (2003): Dynamic MOE of 55 species using small wood beams. Holz als Roh- und Werkstoff 61: 167-172.

Ivković, M., H. X. Wu, T. A. McRae and M. B. Powell (2006): Developing breeding objectives for Pinus radiata structural wood production I: Bioeconomic model and economic weights. Can. J. For. Res 36: 2920-2931.

Johnson, G. R. and B. Gartner (2006): Genetic variation in basic density an modulus of elasticity of coastal Douglas-fir. Tree Genetics and Genomes 3: 25-33.

KUMAR, S. (2004): Genetic parameter estimates for wood stiffness, strength, internal checking and resin bleeding for radiata pine. Can. J. For. Res 34: 2601-2610.

Kumar, S., K. J. S. JaYAWickrama, J. LeE and M. LAUSBERG (2002): Direct and indirect measures of stiffness and strength show high heritability in a wind-pollinated radiata pine progeny test in New Zealand. Silvae Genet. 51: 256-261.

KumAR, S. and L. LEE (2002): Age-age correlations and early selection for end-of-rotation wood density in radiata pine. For. Gen. 9: 323-330.

LI, L. and H. X. WU (2005): Efficiency of early selection for rotation-aged growth and wood density traits in Pinus radiata. Can. J. For. Res. 35: 2019-2029.

LASSARRE, J., E. MASON and M. WATTS (2004): The influence of initial stocking on corewood stiffness in a clonal experiment of 11 -year old Pinus radiata D. Don. N. Z. J. For. Sci. 49: 18-23.

LYNCH, M. and B. WALSH (1998): Genetics and Analysis of Quantitative Traits. Sinauer, Sunderland USA.

Matheson, A. C., K. G. Eldridge, A. G. Brown and D. J. SPENCER (1986): Wood volume gains from first-generation radiata pine seed orchards. CSIRO Division of Forest Research User Series 4. 13pp.

Matheson, A. C., D. J. Spencer and D. Magnussen (1994): Optimum age for selection in Pinus radiata using area under bark for age:age correlations. Silvae Genet. 43: 352-357.

Matheson, A. C., D. J. Spencer, J. G. Nyakuengama, J. L. YANG and R. Evans (1997): Breeding for wood properties in radiata pine. In: BuRdon, R. D.; MooRE, J. M. (Ed.) 1997: "IUFRO '97 Genetics of Radiata Pine". Proceedings of NZFRI-IUFRO Conference 1-4 December and Workshop 5 December, Rotorua, New Zealand. FRI Bulletin No 203. Pp 169-179.

Matheson, A. C., J. L. YANG and D. J. Spencer (1997): Breeding radiata pine for improvement of sawn timber value. In: Timber management toward wood quality and end-product value. (edited by ZHANG, S.Y., Gos-
SELIN, R. and CHAURET, G.). Proceedings of CTIA/ IUFRO international wood quality workshop. IV-19, Quebec, Canada.

Matheson, A. C., R. L. Dickson, D. J. Spencer, B. Joe and J. ILIC (2002): Acoustic segregation of Pinus radiata logs according to stiffness. Ann. For. Sci 59: 471-477.

Matheson, A. C. and H. S. Dungey (2003): Final report on $\mathrm{CSIRO/FR/FWPRDC/RPBC} \mathrm{collaborative} \mathrm{project}$ "Improving wood stiffness through microfibril angle" PN02.1910. CSIRO Forestry and Forest Products Client Report No 1417, 47pp.

Powell, M. B., T. A. McRae, H. X. Wu, G. W. Dutkowski, D. J. Pilbeam (2005): Breeding strategy for Pinus radiata in Australia. pp. 308-318, Pp 308-318 in Proceedings of IUFRO Forest Genetic Meeting (Forest genetics and tree breeding in the age of genomics: progress and future), eds. by B. Li and S. McKEAND.

QuASS, R. L. (1988): Additive genetic model with groups and relationships. J. Dairy Sci. 71: 1338-1345.

Schimleck, L. R., R. Evans, J. Ilic and A. C. Matheson (2002): Estimation of wood stiffness of increment cores by near-infrared spectroscopy. Can. J. For. Res 32: $129-135$.

Shelbourne, C. J. A., L. A. Apiolaza, K. J. S. JayawickRAMA and C. T. SorEnsson (1997): Developing breeding objectives for radiata pine in New Zealand. In: BURDON, R. D.; Moore, J. M. (Ed.) 1997: "IUFRO '97 Genetics of Radiata Pine". Proceedings of NZFRI-IUFRO Conference 1-4 December and Workshop 5 December, Rotorua, New Zealand. FRI Bulletin No 203. Pp 160-17168.

WALKER, J. C. F. and R. NAKADA (1999): Understanding corewood in some conifers: a selective review on stiffness and acoustics. Inter. For. Rev 1: 251-259.

Westell, R. A., R. L. QuAss and L. D. VAN VLECK (1988): Genetic groups in an animal model. J. Dairy Sci. 71: 1310-1318.

White, T. L., A. C. Matheson, P. P. Cotterill, R. G. Johnson, A. F. Rout and D. B. Boomsma (1999): A Nucleus Breeding Plan for Radiata Pine in Australia. Silvae Genet. 48: 122-133.

Williams, E. R., A. C. Matheson and C. E. Harwood (2002): Experimental design and analysis for tree improvement. $2^{\text {nd }}$ edition, CSIRO: Melbourne. $214 \mathrm{pp}$.

Wang, X., F. Divos, C. Pikon, B. K. Brashaw, R. J. Ross and R. F. Pellerin (2004): Assessment of decay in standing timber using stress wave timing non-destructive evaluation tools. USDA Forest Service Forest Products Laboratory General Technical Report FPL-GTR$147,12 \mathrm{pp}$.

Wu, H. X., J. L. Yang, T. A. McRae, L. Li, Ivković and M. B. Powell (2004): Breeding for wood quality and profits with radiata pine, 1: MOE prediction and genetic correlation between early growth, density, microfibril angle and rotation-age MOE. In: Proceedings of Wood Quality 2004: Practical tools \& new technologies to improve segregation of logs and lumber for processing. Albury.

Wu, H. X. and A. C. MATHESON (2002): Quantitative genetics of growth and form traits in radiata pine: Final report on RWG-1 Australia-wide radiata pine diallel project. CSIRO Forestry and Forest Products Divisional Report 138 and STBA Technical Report TR2002-01. 133 pp.

Wu, H. X., M. B. Powell, J. L. YANG, Ivković, and T. A. MCRAE (2007): Efficiency of early selection for rotationaged wood quality traits in radiata pine. Ann. For. Sci. 64: 1-9. 